NOTICE: this is the author's version of a work that was accepted for publication in Journal of Environmental Management. Changes resulting from the publishing process, such as peer review, editing, corrections, structural formatting, and other quality control mechanisms may not be reflected in this document. Changes may have been made to this work since it was submitted for publication. A definitive version was subsequently published in Journal of Environmental Management, [Vol. 146, (2014)] DOI: http://dx.doi.org/10.1016/i.jenvman.2014.08.014 


\title{
Treatment of Metal-Contaminated Wastewater: A comparison of low-cost biosorbents
}

\author{
N. K. AKUNWA ${ }^{a}$, M. MUHAMMAD ${ }^{a}$. and J. C. AKUNNA ${ }^{a b}$ \\ a Urban Water Technology Centre, School of Science, Engineering and Technology, \\ University of Abertay Dundee, DD1 1HG, Scotland
}

${ }^{\mathbf{b}}$ Corresponding author. Urban Water Technology Centre, School of Science Engineering \& Technology, University of Abertay Dundee, DD1 1HG, Scotland. Email:j.akunna@abertay.ac.uk

Tel: +44 (0)1382308141 Fax: +44(0)1382308117

\begin{abstract}
This study aimed to identify some optimum adsorption conditions for the use of lowcost adsorbent, seaweed (Ascophyllum nodosum), sawdust and reed plant (Phragmites australis) root, in the treatment of metal contaminated wastewater for the removal of cadmium, chromium and lead. The effect of $\mathrm{pH}$ on the absorption capacity of each of these biosorbents was found to be significant and dependent on the metal being removed. Post-adsorption FTIR analysis showed significant binding activities at the nitro $\mathrm{N}=\mathrm{O}$ groups site in all biosorbents, especially for lead. Competitive metal binding was found to have possibly affected the adsorption capacity for chromium by A. nodosum more than it affected sawdust and P. australis root. Adsorption is believed to take place mainly by ion exchange particularly at low $\mathrm{pH}$ values. $P$. australis root exhibited the highest adsorption for chromium at $\mathrm{pH} 2$, cadmium at $\mathrm{pH}$ 10 and lead at $\mathrm{pH}$ 7. A.nodosum seaweed species demonstrated the highest adsorption capacity of the three biosorbents used in the study, for cadmium at $\mathrm{pH} 7$ and for lead at $\mathrm{pH}$ 2. Sawdust proved to be an efficient biosorbent for lead removal only at $\mathrm{pH} 7$ and 10. No significant effect of temperature on adsorption capacity was observed, particularly for cadmium and lead removal.
\end{abstract}

Keywords: Adsorption capacity; heavy metals; $\mathrm{pH}$; reed root; sawdust; seaweed 


\section{Introduction}

Heavy metal contamination of industrial effluents has been an issue of environmental and public health concern since the advent of industrialisation, owing to their nonbiodegradable, toxic and bio-accumulative nature (Bailey et al., 1999; Nomanbhay and Palanisamy, 2005). Indicative metals are mostly transition metals like cadmium, copper, zinc, nickel, chromium, as well as other heavy metals such as lead, aluminium, and mercury, amongst others that pose significant risk to soil, water and air environments, their inhabitants and human health via the food chain (Oboh et al., 2009). On discharge of effluents from industries like mining, textile, tannery, metalplating, petro-chemical, battery and fertilizer production, these metals are deposited in soil, aquatic life-forms and tissues, which form part of the human food-chain. Thus, the toxicity, bio-accumulation and persistence of these metals are transmitted through the food chain and the environment to cause environmental and human health problems (Kanamadi et al., 2006). This situation is most prevalent in tropical developing countries where the enforcement of industrial effluent discharge limits is yet to be accorded the priority it deserves, in contrast to developed countries where stringent environmental quality standards to control pollution by industrial effluents and protect the environment are being adopted and enforced (Dan'Azumi and Bichi, 2010).

Conventional treatment methods have been found to be very expensive and difficult to maintain due to high capital and operational costs as well as extra cost of treating the resultant sludge/secondary waste before disposal as it also poses hazards and pollution risks to the environment (Kumar, 2006). Due to these challenges associated with the conventional methods, growing interest and research into the use of low-cost adsorbents as preferred alternatives to the conventional methods has yielded various successful applications of these low-cost, naturally-occurring and readily available organic adsorbents in the treatment of metal-contaminated industrial effluents using adsorption processes, as reported in various studies (Oboh et al., 2009). The distinct advantages of biosorbents include: low cost, high efficiency, reduced production of chemical or biological sludge, possibility of regeneration of biosorbents and metal recovery (Sud et al., 2008).

Seaweed, sawdust and reed plant root are some of the low-cost readily available organic residues, found naturally in the environment and are considered 
waste or by-products. Ascophyllum nodosum is considered an effective seaweed for metal adsorption (Romera et al., 2006) and macroscopically produces biosorbent particles, conferring on it a better metal-binding capacity than most organic or inorganic adsorbents (Freitas et al., 2006). Seaweed is reportedly rich in three main polysaccharides - laminaran, fucoidin and alginate, which are rich in anionic carboxylate and sulphate ready for binding at neutral pH (Alluri et al., 2007). The alginate polysaccharide is responsible for its ion-exchange capacity due to its high concentration of carboxyl groups (Mehta and Gaur, 2005; Freitas et al., 2009). The binding surface of seaweed is rich in functional groups like carboxyl, hydroxyl, amine, imidazole, phosphate, sulfhydryl and sulphate groups. However, the carboxyl and sulphate groups are reputably the most active groups in the binding of metals during adsorption (Romera et al., 2007).

Sawdust, a by-product of the timber industry, which is considered waste except when it is used as packaging material (Vinodhni and Das, 2010) or as cooking fuel, is abundantly available to the point of constituting disposal challenges in timber mills, especially in developing countries. Sawdust consists of three dominant components: cellulose, lignocellulose and lignin, based on which its functional groups reputed to be actively involved in adsorption include $\mathrm{C}=\mathrm{CH}, \mathrm{C}=\mathrm{C}, \mathrm{C}-\mathrm{OH}$ and $\mathrm{C}-\mathrm{O}-\mathrm{C}$ groups (Abdel-Ghani et al., 2007). Its main mechanisms of adsorption are ion exchange and hydrogen binding (Shukla et al., 2002), as well as, chelation and complexation reactions (Asadi et al., 2008).

Reed plant, Phragmites australis, is a perennial helophyte grass commonly found in tropical and temperate wetlands where it grows rapidly and exhibits outstanding tolerance of high metal concentrations (Batty, 2003). It is the most commonly employed plant species in the treatment and polishing of wastewater in constructed wetlands where it enhances the break-down organic pollutants by adsorption, accumulation and oxidation via aeration systems around the root zones (Lee and Scholz, 2007). Reed plant contains high concentrations of lignin and cellulose, two components believed to play important roles in its adsorptive capacity for various heavy metals from solution (Southichak et al., 2006). Carboxylic, carboxylate, lignin and lignin ester aromatic C-C groups have been revealed to actively contribute in adsorptive capacity (Southichak et al., 2006), irrespective of 
contrasting research reports on its suitability as a biosorbent (Batty, 2003) or otherwise (Lee and Scholz, 2007).

The aim of this study is to identify optimum adsorption conditions for the use of seaweed (Ascophyllum nodosum), sawdust and reed plant (Phragmites australis) root in the removal of cadmium, chromium and lead from metal-contaminated wastewaters. Cadmium and lead constitute two of the three heavy metals listed by the World Health Organisation (WHO) as the 'Big Three' toxic metals, along with Mercury, while chromium was selected because of its ubiquitous presence in various industrial effluents, which are of interest in this study.

\section{Materials and methods}

\subsection{Collection and preliminary treatment of biosorbent samples}

The seaweed sample was collected from the beaches of Abroath, Scotland. The reed plant sample was collected from reed-beds in the mini wastewater treatment works serving the Belmont Centre, located in Miegle near Dundee, Scotland and the sawdust sample was collected from the University of Abertay Dundee wood works workshop.

\subsection{Preliminary treatment/Preparation of biosorbent samples}

The biosorbents were devoid of any chemical pre-treatment or immobilisation and were used in their natural forms after washing and drying. Samples of seaweed (SW) reed (RR) plant and sawdust (SD) used were collected separately. Prior to any preparation, reed plant root was separated from the leaves by cutting. Seaweed and reed plant root were washed separately using tap water, followed by distilled water to remove the sand and stones entangled in the root systems of each sample. Both biosorbent samples were then dried separately in the oven at $105^{\circ} \mathrm{C}$ for 24 hours. Sawdust was cleaned by hand-picking visible contaminants like wood-splinters and then oven-dried at $105^{\circ} \mathrm{C}$ for only 3 hours. To optimise the available surface area for the adsorption process, each of the three samples was blended into a powder using a commercial blender and further reduced to finer particles by a $0.5 \mathrm{~mm}$ particle-size rotor mill (Fritsch Rotor Speed Mill-Pulverisette 14). Samples were stored separately in clearly-labelled, air-tight, transparent containers at room temperature until required for use. 


\subsection{Preparation of metal stock standard and dilute solutions}

Stock standard solution of each metal was prepared to the strength $1000 \mathrm{mg} / \mathrm{l}$. The procedure for stock standard solution preparation was as follows: Each of $1 \mathrm{~g}$ of pure cadmium metal (powder form supplied by BDH), $3.735 \mathrm{~g}$ of potassium chromate, $\mathrm{K}_{2} \mathrm{CrO}_{4}$ and $1.598 \mathrm{~g}$ of lead nitrate, $\mathrm{Pb}(\mathrm{NO})_{3}$, was weighed on an Oertling NA 114 scale and put into a separate $100 \mathrm{ml}$ beaker.

Cadmium was dissolved in a mixed solution of $15 \mathrm{ml}$ each of deionised water and concentrated $\mathrm{HCl}$ to give a clear solution and heated for 10 minutes. It was allowed to cool and made up to 1 litre solution with $1 \%(\mathrm{v} / \mathrm{v}) \mathrm{HCl}$. Potassium chromate was dissolved in $40 \mathrm{ml}$ of deionised water to give a yellow-coloured solution and diluted to 1 litre with more deionised water. Lead nitrate was dissolved in $40 \mathrm{ml}$ of $1 \%(\mathrm{v} / \mathrm{v}) \mathrm{HNO}_{3}$. The solution was heated for 2 minutes and allowed to cool at room temperature before being made up to 1 litre with more $1 \%(\mathrm{v} / \mathrm{v}) \mathrm{HNO}_{3}$. Each solution was then stored in a clearly-labelled 1litre clear-glass reagent bottle.

\subsection{Initial characterisation of biosorbents}

\subsubsection{Determination of initial metal content of biosorbents}

The initial metal content of the biosorbents was determined using the dry ashing and wet digestion methods. This initial metal content determination was deemed necessary in order to determine the actual amount of heavy metals under study present in the biosorbents prior to the adsorption experiments.

\subsubsection{Dryashing}

Duplicates of $1 \pm 0.005 \mathrm{~g}$ each of seaweed, reed plant root and sawdust dry powder samples was weighed and placed in porcelain crucibles. The crucibles were then placed in the furnace overnight at $550^{\circ} \mathrm{C}$ for ashing. The ashed samples were then allowed to cool down at room temperature for approximately 10 minutes and then introduced into $5 \mathrm{ml}$ of $20 \% \mathrm{HCl}$ to dissolve the residue. The $20 \% \mathrm{HCl}$ was prepared by adding $20 \mathrm{ml}$ of concentrated $\mathrm{HCl}$ to $80 \mathrm{ml}$ of distilled water in a $100 \mathrm{ml}$ conical flask. Each solution was then filtered by suction force through an acid-washed filter paper placed in a filter-flask. The filter paper was then rinsed into the solution in the filter-flask before being transferred into a $50 \mathrm{ml}$ volumetric flask where it was diluted to volume with distilled water before mixing. The liquid samples were then 
stored at $4{ }^{\circ} \mathrm{C}$ in a refrigerator for 10 days before analysis using a Perkin Elmer AAnalyst 200 Atomic Absorption Spectrophotometer (AAS).

\subsubsection{Wet digestion}

$10 \mathrm{ml}$ of concentrated $\mathrm{HNO}_{3}$ was added to $1 \pm 0.005 \mathrm{~g}$ of each dry powder biosorbent sample in a $100 \mathrm{ml}$ beaker and allowed to stand overnight. Each beaker was then heated on a hot-plate until the production of red $\mathrm{NO}_{2}$ fumes ceased. Each beaker was then cooled and $2 \mathrm{ml}$ of $70 \% \mathrm{HClO}_{4}$ (Perchloric acid) added. Samples were heated a second time and allowed to evaporate to a much reduced volume before being transferred to a $50 \mathrm{ml}$ volumetric flask and diluted to volume with distilled water. The samples from both digestion processes were then analysed for presence of each of the metals under study using Atomic Absorption Spectrometry (AAS).

\subsubsection{Determination of functional group distribution within biosorbent samples using} Fourier Transform Infrared Spectroscopy (FTIR)

A pre- and post adsorption determination of the types and distribution of functional groups or bonds present in dry biosorbent samples was carried out by Fourier Transform Infrared Spectroscopy using the Perkin Elmer FT-Infra Red Spectrometer: Spectrum RX1. This determination was to facilitate identification of the functional groups responsible for metal binding on each biosorbent surface (Jin and Bai, 2002). Matching the wavelength of light absorbance to standard bond or functional group types that absorbs light energy at that standard wavelength would achieve the identification.

For the FTIR spectroscopy, Potassium Bromate $(\mathrm{KBr})$ crystals were mixed in a ratio of 8:1 with each dry biosorbent sample and blended into a fine powder, which was used to form uniform $\mathrm{KBr}$ glass-like pellets. Automatic Infra-red spectra were then plotted out by the spectrometer. The FTIR spectrometry readings were carried out at specific wavelengths and slits for each metal under study viz: cadmium (228.80 $\mathrm{nm}$ and 0.7$)$, chromium (357.87 $\mathrm{nm}$ and 2.7/0.8) and lead (217.00 $\mathrm{nm}$ and 2.7/1.35).

For all three metals used in this study, readings were done in triplicate. Integration time was 3 seconds, read delay was 5 seconds, unit of measurement was $\mathrm{mg} / \mathrm{l}$ and calibration equations were all linear through zero. The spectra were then printed out for analysis. 


\subsection{Adsorption capacity experiment design}

The adsorption experiments were carried out in batch mode and in duplicates for each metal and biosorbent.

\subsubsection{Factors affecting the adsorption process}

The factors affecting the adsorption capacity of the three biosorbents were divided into two groups: constant and variable factors.

\subsubsection{Constant factors}

Constant factors were not varied throughout the adsorption experiments. These included (a) the initial metal concentration, fixed at $200 \mathrm{mg} / \mathrm{l}$, (b) biosorbent dose, $1 \pm$ $0.005 \mathrm{~g}$ per sample of metal solution, (c) maximum particle size of $0.5 \mathrm{~mm}$ for all biosorbent samples (d) contact time per adsorption experiment, 3 hours. It has been reported that about $75 \%$ adsorption is usually attained within $30-60$ minutes (Souag et al., 2009) while equilibrium is usually attained after about 2 hours of adsorption (Fujiwara et al., 2007).

\subsubsection{Variable factors}

Two temperature levels, $23.5^{\circ} \mathrm{C}$ and $37^{\circ} \mathrm{C}$ were used in the study. Both temperatures represent the higher average and maximum temperatures obtainable in most tropical countries, The effect of $\mathrm{pH}$ on the adsorption process was studied at four $\mathrm{pH}$ values- 2, 5, 7 and 10. Four different solutions containing $200 \mathrm{mg} / \mathrm{l}$ of each of three metals used for the study $(\mathrm{Cr}, \mathrm{Pb}$ and $\mathrm{Cd})$ were prepared for each metal and adjusted to each of the four chosen $\mathrm{pH}$ values using concentrated ammonium hydroxide, concentrated $\mathrm{HCl}$ or concentrated $\mathrm{HNO}_{3}$. A Hanna Educational $\mathrm{pH}$ Meter HI 208 was used in reading the $\mathrm{pH}$ values.

\subsubsection{Adsorption experiments}

The adsorption experiments were carried out in a batch mode. $1 \pm 0.005 \mathrm{~g}$ of each biosorbent was weighed into $60 \mathrm{ml}$ plastic centrifuge tubes in three sets of duplicates for the three metals. $50 \mathrm{ml}$ of each $200 \mathrm{mg} / \mathrm{l}$ metal solution was added to the tubes containing each biosorbent type and shaken by hand at room temperature for approximately 30 seconds to ensure proper mixing of biosorbents and metals in solution. Tubes containing samples were then allowed to stand for 3 hours but were 
shaken again 1.5 hours into the three hours for better biosorbent-metal ion contact. At the end of the 3 hours contact time, the samples were centrifuged for 20 minutes each at a speed of $5400 \mathrm{rpm}$ (rotations per minutes), using an Impact-5 Centrifuge. Centrifugation was followed by the separation of the supernatants from the biosorbents by decantation and filtration using Fisherbrand QL 100 filter paper.

\subsubsection{Determination of residual metal concentration in supernatant}

The residual or post-adsorption concentration of each metal was determined using the standard method of Direct Air-Acetylene Flame Atomic Adsorption Spectroscopy (AAS). Prior to the AAS analysis, the cadmium and chromium solution filtrates were diluted by a factor of 100 to reduce the concentration to $2 \mathrm{mg} / \mathrm{l}$ to meet the linear range for the AAS instrument. Lead was diluted by a factor of 10 down to a concentration of $20 \mathrm{mg} / \mathrm{l}$, within the linear range for AAS measurement of lead. Residual concentration of each metal was then analysed using the specified lamp for each metal and at designated wavelengths. The adsorption capacity, depicted by the amount of each metal adsorbed by the respective biosorbents, was obtained by calculating the difference between the initial amount of metal ions added to the biosorbent and the residual amount of metal ions remaining in the post-centrifugation supernatant after adsorption using the formula: $\mathrm{Q}=\underline{\left(\mathrm{C}_{\mathrm{o}}-\mathrm{C}_{\mathrm{f}}\right)} \mathrm{V} / \mathrm{M}$, where $\mathrm{Q}=$ Amount of metal adsorbed $(\mathrm{mg} / \mathrm{g}), \mathrm{C}_{\mathrm{o}}=$ Initial metal concentration in solution $(\mathrm{mg} / \mathrm{l})$, $\mathrm{C}_{\mathrm{f}}=$ Final metal concentration in supernatant after adsorption $(\mathrm{mg} / \mathrm{l}), \mathrm{V}=$ Volume of solution (l) and $\mathrm{M}=$ Mass of the biosorbent (g), which in this experiment was approximately $1 \mathrm{~g}$.

\section{Results and discussion}

\subsection{Initial characterisation of biosorbents}

Initial characterisation of biosorbents entailed the pre-adsorption determinations of metal content of biosorbents and functional group distributions within each biosorbent samples.

\subsubsection{Determination of initial metal content of biosorbents}

Initial metal content determination per biosorbent revealed that of all three metals analysed, chromium had the highest pre-adsorption concentration of between 
0.30-0.45 mg per gram of each biosorbent, in the order $\mathrm{SW}>\mathrm{RR}>\mathrm{SD}$ as shown in Table 1.

\section{Table 1}

Initial metal ion concentration per gram of biosorbent

\begin{tabular}{llll}
\hline $\begin{array}{l}\text { Biosorbent } \\
\text { type }\end{array}$ & Metal ion & \multicolumn{2}{l}{ Initial metal content determination by: } \\
Seaweed & $\mathrm{Cd}$ & 0.02 & Dry ashing $(\mathrm{mg} / \mathrm{g})$ \\
& $\mathrm{Cr}$ & 0.34 & 0.00 \\
& $\mathrm{~Pb}$ & 0.01 & 0.45 \\
Sawdust & $\mathrm{Cd}$ & 0.00 & 0.01 \\
& $\mathrm{Cr}$ & 0.30 & 0.12 \\
& $\mathrm{~Pb}$ & 0.00 & 0.32 \\
Reed Root & $\mathrm{Cd}$ & 0.00 & 0.02 \\
& $\mathrm{Cr}$ & 0.31 & 0.00 \\
& $\mathrm{~Pb}$ & 0.03 & 0.33 \\
& & & 0.00 \\
\hline
\end{tabular}

The relatively high pre-adsorption concentration of chromium in all three biosorbent samples may affect its adsorption capacity.

\subsubsection{Determination of functional group distribution within biosorbent samples}

Pre-adsorption FTIR results indicate strong presence of such groups as the carboxylic acid or alcoholic O-H bond stretching which may overlap with amine $(\mathrm{N}$ $\mathrm{H})$ bond stretching at peaks between $3250-3400 \mathrm{~cm}^{-1}$ for all three biosorbents. Possible $\mathrm{C}-\mathrm{H}$ bond stretchings of alkanes at peaks just below $3000 \mathrm{~cm}^{-1}$; $\mathrm{C}=\mathrm{O}$ bond of carbonyl or amide groups within $1640-1670 \mathrm{~cm}^{-1}$; C-O and $\mathrm{O}-\mathrm{H}$ bond stretchings of alcohol and ethers at $1000-1260 \mathrm{~cm}^{-1}$ of the finger-print region; the aromatic $\mathrm{C}-\mathrm{H}$ bond bends at $690-900 \mathrm{~cm}^{-1}$ and possible sulphate or sulfoxide $\mathrm{S}=\mathrm{O}$ bond around $1050 \mathrm{~cm}^{-1}$ were also observed for only sawdust and reed plant root. Comparison of pre and post-adsorption FTIR results showed only slight changes in the pre-adsorption results, suggesting probable uniformity in manner of adsorption, as all three adsorbents are organic in nature and may bind metals in similar manners. 
For the seaweed, no significant change was observed after chromium adsorption with seaweed, which may possibly be due to competitive binding by high pre-adsorption chromium ions. Lead adsorption showed a strikingly deeper trough at $1384.5 \mathrm{~cm}^{-1}$ indicating possible binding to the nitro $\mathrm{N}=\mathrm{O}$ stretching. With sawdust, all three metals caused slightly deeper troughs at $1033 \mathrm{~cm}^{-1}$ and $1059 \mathrm{~cm}^{-1}$ suggesting metal binding to amine $\mathrm{C}=\mathrm{N}$ bonds. Changes were observed at $1508.3 \mathrm{~cm}^{-1}$ and $1384.4 \mathrm{~cm}^{-1}$ for chromium and lead respectively, suggesting binding to nitro $\mathrm{N}=\mathrm{O}$ bonds. With reed plant (P.australis) root, the major change observed was at 1384.4 $\mathrm{cm}^{-1}$ with lead adsorption, suggesting binding to nitro $\mathrm{N}=\mathrm{O}$ bonds. These identified regions may be indicative of functional groups responsible for the individual metalbinding activity of each biosorbent, apart from the groups indicated in previous studies (Kanamadi et al., 2006).

\subsection{Adsorption capacity of absorbents}

The results stated were mean absorbent values of duplicated experiments.

\subsubsection{Effect of temperature}

Experiments carried out with temperature being the sole variable, showed that for a given adsorbent, metal ion and $\mathrm{pH}$ value used in the study, there was no significant difference between adsorption capacities at $23.5^{\circ} \mathrm{C}$ and at $37^{\circ} \mathrm{C}$.

\subsubsection{Effect of initial $p H$}

Figures 1, 2 and 3 show the variation of adsorption capacity with $\mathrm{pH}$ for the three biosorbents. Adsorption of cadmium was observed to increase with increasing $\mathrm{pH}$, being highest at $\mathrm{pH} 10$ for all three biosorbents studied as shown in Fig. 1. Adsorption of chromium was observed to generally decrease with increasing $\mathrm{pH}$ with its highest adsorption occurring at $\mathrm{pH} 2$ and no adsorption occurring at $\mathrm{pH} 10$ as shown in Fig. 2. At $\mathrm{pH}$ 2, reed plant root exhibited the highest adsorption capacity indicating its highest removal efficiency in acidic solutions. No adsorption for chromium by seaweed was observed throughout the $\mathrm{pH}$ range while chromium adsorption by sawdust was significant only at $\mathrm{pH} 2$. The relatively high preadsorption concentration of chromium in all three biosorbent samples, shown in Table 1, might have affected adsorption capacity of chromium ions in solution due to competitive binding at the biosorbent chromium-binding sites. 
Figure 3 shows that with lead, adsorption capacity decreased with increasing $\mathrm{pH}$ for seaweed, increased with increasing $\mathrm{pH}$ for sawdust and increased to maximum adsorption at $\mathrm{pH} 7$ for reed plant root before decreasing in alkaline solutions. For sawdust, lead adsorption increased rapidly and steadily with increase in $\mathrm{pH}$, suggesting increasing capacity for lead uptake from acidic to alkaline solutions, with a maximum adsorption capacity of $183.33 \mathrm{mg} / \mathrm{g}$ of lead at $\mathrm{pH} 10$. For reed plant root, a consistently high rate of lead uptake was observed throughout the $\mathrm{pH}$ range, suggesting the biosorbent's high efficiency in lead removal from both acidic and alkaline solutions and this characteristic may qualify reed plant root as a biosorbent of choice for various types of industrial effluents as most effluents generally do not have singular $\mathrm{pH}$ values.

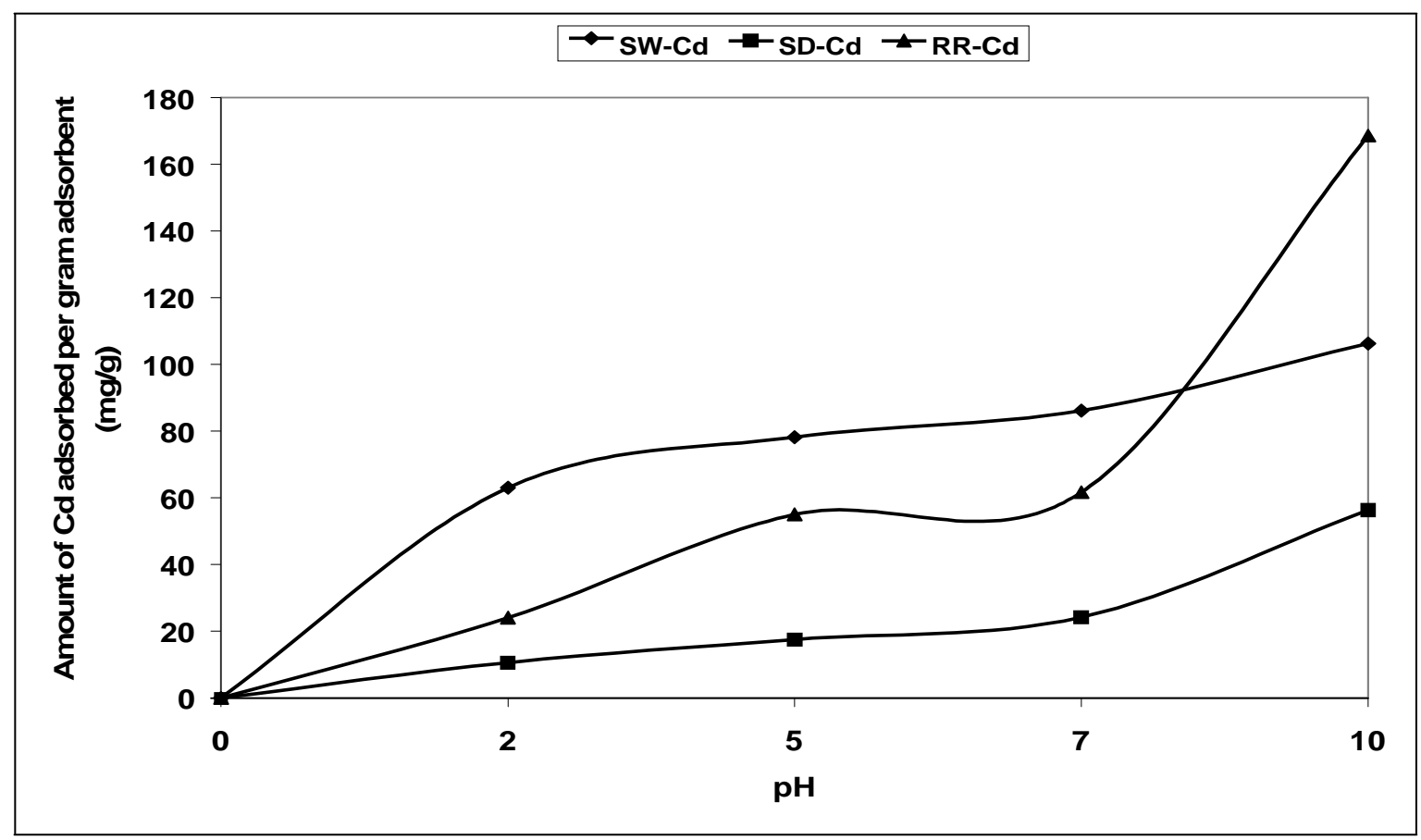

Figure1. Effect of pH on cadmium ion adsorption using seaweed (SW-Cd), sawdust (SD-Cd) and reed plant root (RR-Cd) 


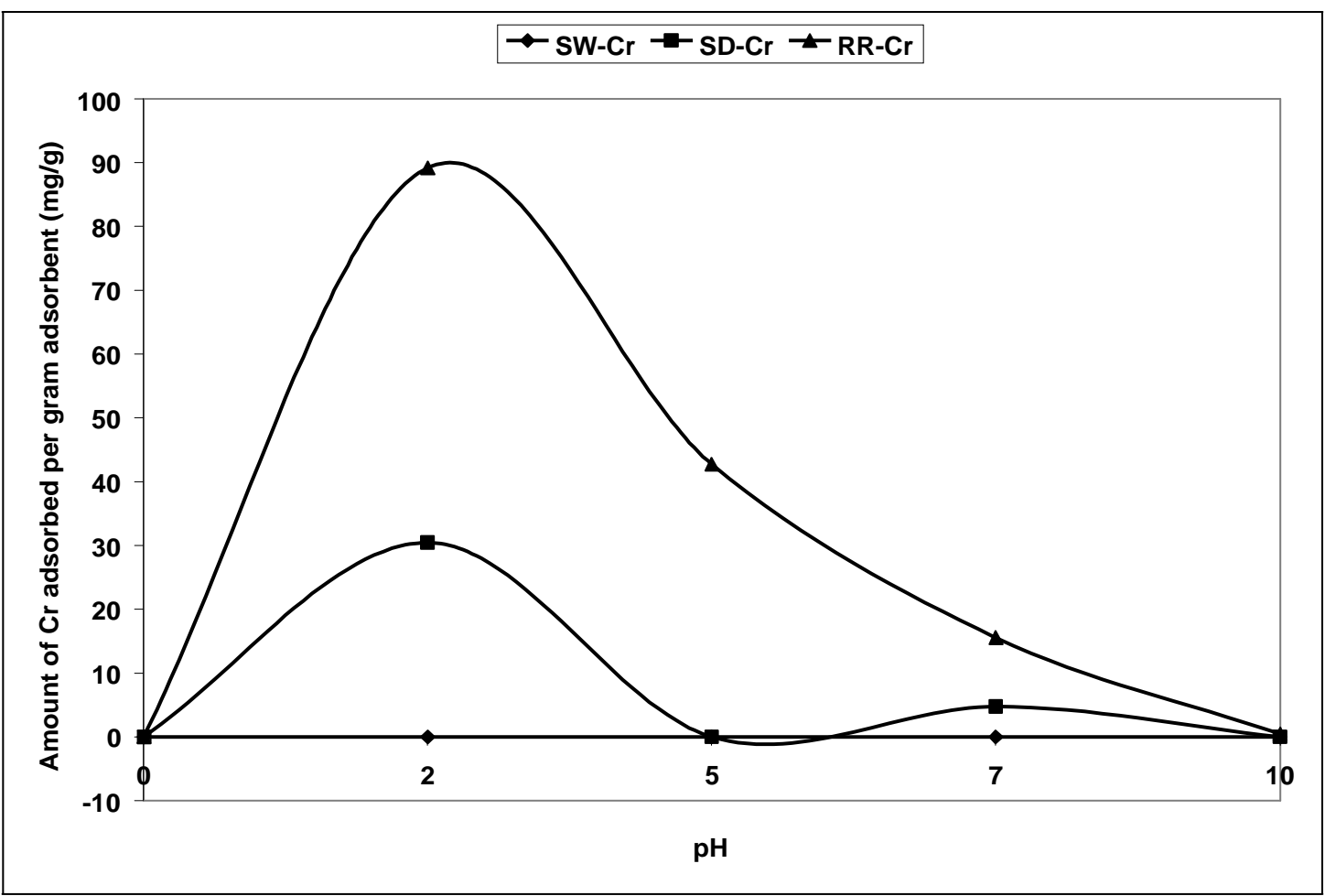

Figure 2. Effect of $\mathrm{pH}$ on chromium adsorption using seaweed (SW-Cr), sawdust (SD-Cr) and reed plant root (RR-Cr)

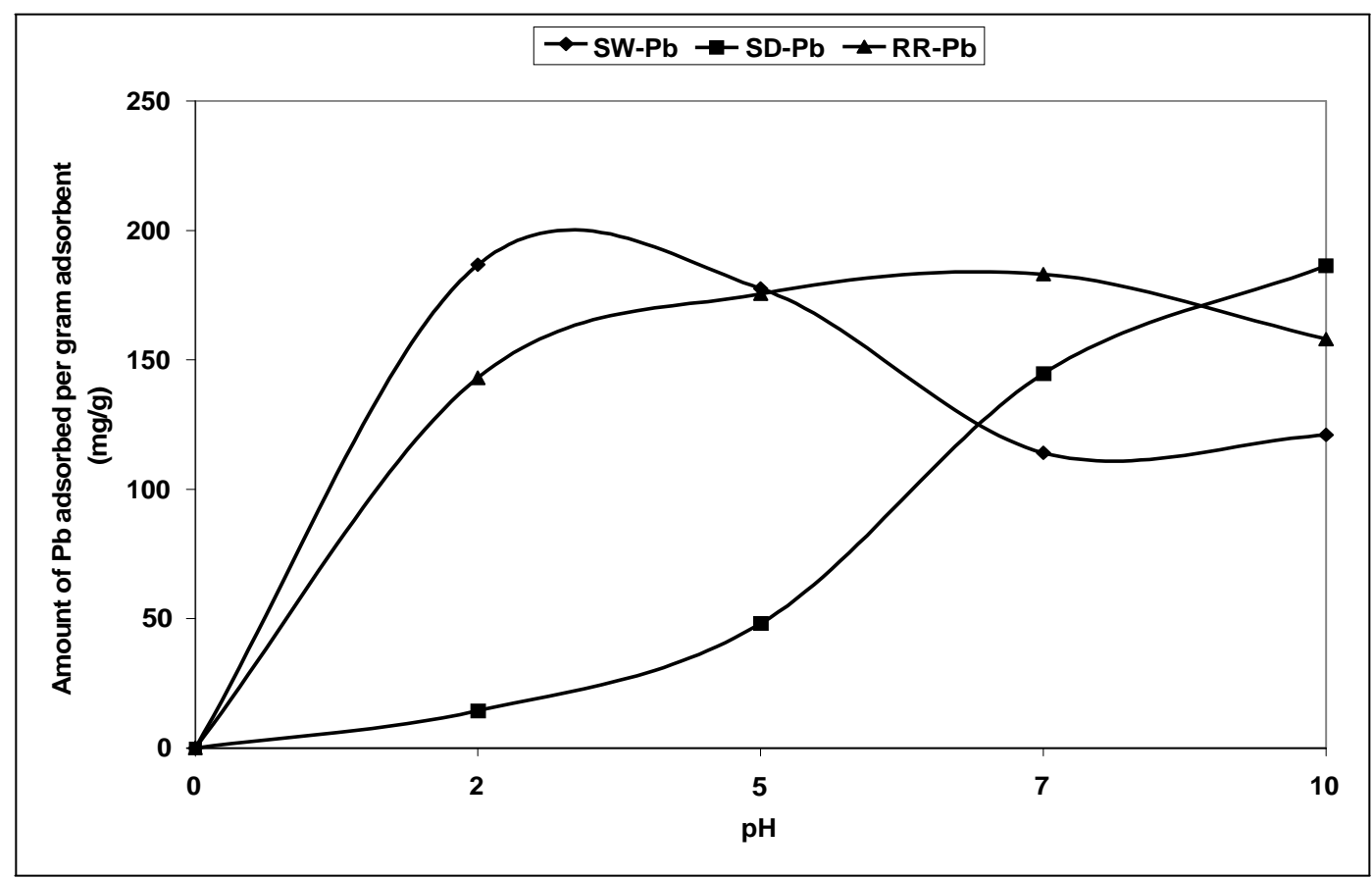

Figure 3. Effect of $\mathrm{pH}$ on lead adsorption using seaweed (SW-Pb), sawdust (SD-Pb) and reed plant root $(\mathrm{RR}-\mathrm{Pb})$ 


\section{Discussion}

Figure 4 summarises the adsorptive capacities of each biosorbent for the metals used in the study.

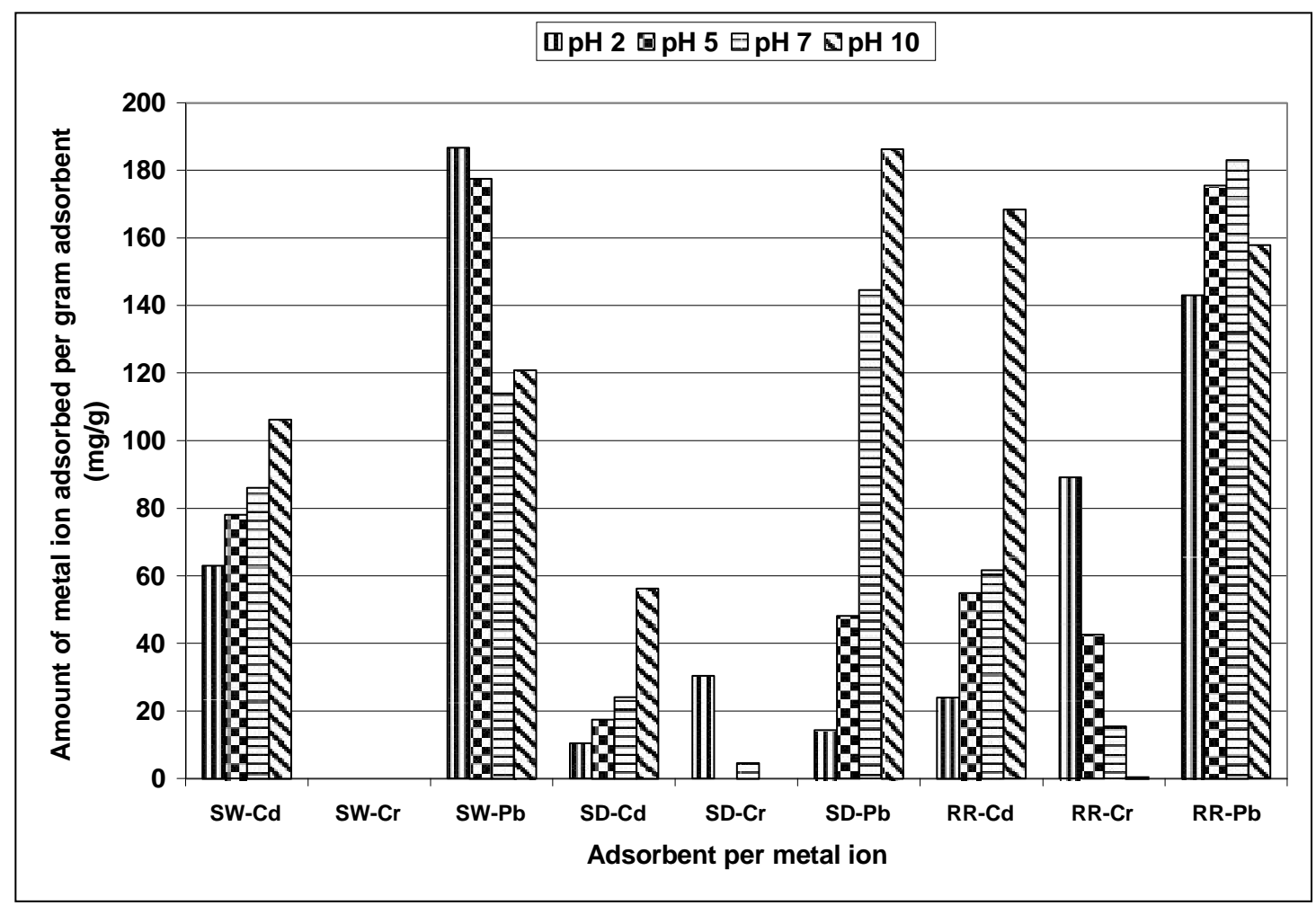

Figure 4. Overall comparison of adsorption capacities of seaweed (SW), sawdust (SD) and reed plant root $(\mathrm{RR})$ for cadmium $(\mathrm{Cd})$, chromium $(\mathrm{Cr})$ and lead $(\mathrm{Pb})$

For cadmium adsorption, seaweed exhibited the most consistent adsorption throughout the $\mathrm{pH}$ range. However, its highest cadmium removal of $106.26 \mathrm{mg}$ at $\mathrm{pH}$ 10 is far less than the $168.56 \mathrm{mg}$ removed by reed plant root at the same $\mathrm{pH}$, suggesting that reed plant root may possess superior cadmium removal efficiency in alkaline solutions. Conversely, seaweed removal of $86.16 \mathrm{mg}$ of cadmium at $\mathrm{pH} 7$ exceeds the $61.70 \mathrm{mg}$ removed by reed plant root and that may be indicative of seaweed's better capacity for cadmium adsorption at or near neutral $\mathrm{pH}$ values. Sawdust exhibited a generally low adsorptive capacity for cadmium throughout the study. Hence, it appears to be the least efficient biosorbent for cadmium in this study. 
Chromium adsorption of $89.20 \mathrm{mg}$ by reed plant root and $30.46 \mathrm{mg}$ by sawdust at $\mathrm{pH} 2$ suggests that, of the three biosorbents studied, reed plant root demonstrated the highest affinity for chromium ions in acidic solutions, followed by sawdust, which appears to lack efficiency in chromium removal throughout the rest of the studied $\mathrm{pH}$ range. Seaweed demonstrated no chromium adsorption capacity throughout this study, and as such, may be considered the least efficient in chromium removal from solution.

Lead removal from solution was consistently high for all three biosorbents studied. Reed plant root exhibited the most consistent lead removal cumulatively with highest removal of $183.06 \mathrm{mg}$ occurring at $\mathrm{pH}$ 7, suggesting the highest lead removal efficiency of reed plant root may be in neutral or near-neutral $\mathrm{pH}$ effluents. Lead adsorption by seaweed remained relatively high in acidic $\mathrm{pH}$ values with highest adsorption of $186.82 \mathrm{mg}$ at $\mathrm{pH} \mathrm{2}$, indicating optimal lead removal efficiency of seaweed in acidic solutions. However, lead adsorption by sawdust was only high at $\mathrm{pH} 7$ and 10 with its highest removal of $186.32 \mathrm{mg}$ occurring at $\mathrm{pH} 10$, suggesting optimal lead removal efficiency for sawdust in alkaline effluents.

A central deduction emerging from the above trends in efficiency is that biosorbent efficiency in metal ion removal varies with wastewater effluent $\mathrm{pH}$. This is because metal binding would depend on the availability, types and concentrations of functional groups on the biosorbent surface at different $\mathrm{pH}$ values. However, in considering the practical application of biosorbents in industrial wastewater treatment in relation to $\mathrm{pH}$, extreme acidic or alkaline $\mathrm{pH}$ values are not considered desirable and environmentally-safe and as such, near-neutral or neutral $\mathrm{pH}$ is considered the most suitable as it approximates the $\mathrm{pH}$ of most oceans and seas into which treated wastewater is discharged. It would also entail the least health and safety requirements, little or no chemicals for further treatment of the effluent after metal adsorption before discharge and would not alter the $\mathrm{pH}$ of the receiving water environment. However, care must be taken in deciding the optimal $\mathrm{pH}$ for a biosorbent as the final $\mathrm{pH}$ of the effluent after adsorption may vary from the initial $\mathrm{pH}$, depending on the amount of $\mathrm{H}^{+}$ and $\mathrm{OH}^{-}$ions released during the adsorption process. Table 2 shows the biosorbent with the highest adsorptive capacity for each metal ion at each $\mathrm{pH}$ value. 


\section{Table 2}

Biosorbent with highest removal capacity at each $\mathrm{pH}$ value

\begin{tabular}{lllll}
\hline Metals & \multicolumn{4}{c}{ Biosorbent with highest metal-removal capacities at each pH: } \\
& $\mathrm{pH} \mathrm{2}$ & $\mathrm{pH}$ & $\mathrm{pH} \mathrm{7}$ & $\mathrm{pH} 10$ \\
\hline Cadmium & $\mathrm{SW}$ & $\mathrm{SW}$ & $\mathrm{SW}$ & $\mathrm{RR}$ \\
Chromium & $\mathrm{RR}$ & $\mathrm{RR}$ & $\mathrm{RR}$ & - \\
Lead & $\mathrm{SW}$ & $\mathrm{SW}$ & $\mathrm{RR}$ & $\mathrm{SD}$ \\
\hline
\end{tabular}

\section{Conclusion and perspectives}

Results from this study have shown that some low-cost biosorbents may be suitable for the treatment of some metal contaminated wastewaters under certain conditions, with $\mathrm{pH}$ playing a more significant role temperature on treatment efficiency. Competitive metal binding was found to significantly affect seaweed's (A. nodosum) adsorption capacity for chromium than it affected sawdust and reed plant $(P$. australis) root. Adsorption was found to occur throughout $\mathrm{pH}$ range but especially at low $\mathrm{pH}$ values. Post-adsorption functional group distribution analysis indicates significant binding activities at the site of the nitro $\mathrm{N}=\mathrm{O}$ groups in all biosorbents, especially for lead. Reed plant root was found to be most efficient biosorbent for chromium at $\mathrm{pH}$ 2, for cadmium at $\mathrm{pH} 10$ and for lead at $\mathrm{pH} 7$. Seaweed yielded the highest adsorption capacity for cadmium at $\mathrm{pH} 7$ and for lead at $\mathrm{pH}$ 2. Sawdust proved to be an effective biosorbent for lead removal only at $\mathrm{pH} 7$ and 10 . This study indicates that waste water treatment in developing countries could be assisted by low cost biosorbents, with wastewater $\mathrm{pH}$ being more important than temperature for the adsorbents and metals used in this study. Further study could consider the most appropriate combination of biosorbents and pretreatment requirements for specific industrial waste waters applications.

\section{Acknowledgements}

The authors would like to thank the University of Abertay Dundee for financially supporting this study. Many thanks also go to Julliette O'Keeffe for her assistance in editing the manuscript. 


\section{References}

Abdel-Ghani, N.T., Hefny, M. and El-Chaghaby, G.A.F. 2007. Removal of Lead from Aqueous Solution using Low Cost Abundantly Available Adsorbents. International Journal of Environmental Science and Technology. 4(1), 67-73.

Alluri, H.M, Ronda, S.R, Settalluri, V.S, Bondili, J.S, Suryanarayana, V. and Venkateshwar, P. 2007. Biosorption: An Eco-friendly Alternative for Heavy Metal Removal. African Journal of Biotechnology. 6 (25), 2924-2931.

Asadi, F., Shariatmadari, H. and Mirghaffari, N. 2008. Modification of Rice Hull and Sawdust Sorptive Characteristics for Removal of Heavy Metals from Synthetic Solutions and Wastewater. Journal of Hazardous Materials. 154(1-3), 451-458.

Batty, L.C. 2003. Wetland Plants-More than just a Pretty Face? Land Contamination and Reclamation. 11(2), 173-180.

Dan'Azumi, S. and Bichi, M.H. 2010. Industrial Pollution and Heavy Metals Profile of Challawa River in Kano, Nigeria. Journal of Applied Sciences in Environmental Sanitation. 5(1), 23-29.

Freitas, O., Boaventura, R and Delerue-Matos, C. 2006. Adsorption Study of Lead By Ascophyllum nodosum using a Factorial Experimental Design. Combined and Hybrid Adsorbents. pp 269-274. [Online]. Available from:

http://www.springerlink.com/content/j303644865752r31/(Accessed 10/08/2010).

Freitas, O., Delerue-Matos, C. and Boaventura, R. 2009. Optimization of $\mathrm{Cu}$ (II) Biosorption onto Ascophyllum nodosum by Factorial Design Methodology. Journal of Hazardous Materials. 167(1-3), 449-454.

Kanamadi, R.D., Ahalya, N. and Ramachandra, T.V. 2006. Biosorption of Heavy Metals by Low-Cost Adsorbents. CES Technical Report-112. Energy and Wetlands Research Group. Available from: 
http://wgbis.ces.iisc.ernet.in/biodiversity/pubs/ces_tr/TR112_Ahalya/index.htm\#objec tives (Accessed 2/07/2010).

Kumar, U. 2006. Agricultural Products and By-products As a Low-cost Adsorbent for Heavy Metal Removal from Water and Wastewater: A Review. Scientific Research and Essay. 1(2): pp 033-037. Available from: http://www.academicjournals.org/SRE (Accessed 23/05/2010).

Lee, B. and Scholz, M. 2007. What is the Role of Phragmites Australis in Experimental Constructed Wetland Filters Treating Urban Runoff? Ecological Engineering. 29(1), 87-95.

Mehta, S.K. and Gaur, J.P. 2005. Use of Algae for Removing Heavy Metal Ions from Wastewater: Progress and Prospects. Critical Reviews in Biotechnology. 25, 113-152.

Nomanbhay, S.M and Palanisamy, K. 2005. Removal of Heavy Metal from Industrial Wastewater Using Chitosan-coated Oil Palm Charcoal. Electronic Journal of Biotechnology ISSN: 0717-3458. 8(1). [Online]. Available from: http://www.ejbiotechnology.info/content/vol8/issue1/full/7/(Accessed22/05/2010).

Oboh, I., Aluyor, E. and Audu, T. 2009. Biosorption of heavy meatl ions from Aqueous Solutions Using a Biomaterial. Leonardo Journal of Sciences. 14, 58-65.

Romera, E., Gonzalez, F., Ballester, A., Blazquez, M.L. and Munoz, J.A. 2006. Biosorption with Algae: A Statistical Review. Critical Reviews in Biotechnology. 26, 223-235.

Romera, E., Gonzalez, F., Ballester, A., Blazquez, M.L. and Munoz, J.A. 2007. Comparative Study of Biosorption of Heavy Metals using Different Types of Algae. Bioresource Technology. 98, 3344-3353.

Shukla, A., Zhang, Y., Dubey, C., Margrave, J.L and Shukla, S. 2002. The Role of Sawdust in the Removal of Unwanted Materials from Water. Journal of Hazardous Materials. 95, 137-152. 
Southichak, B., Nakano,K., Nomura, M., Chiba,N. and Nishimura, O. 2006. Phragmites australis: A Novel Biosorbent for the Removal of Heavy Metals from Aqueous Solution. Water Research. 40(12), 2295-2302.

Sud, D, Mahajan, G. and Kaur, M.P.2008. Agricultural Waste Material as Potential Adsorbent for Sequestering Heavy Metal Ions from Aqueous Solutions - A Review. Bioresource Technology. 99(14), 6017-6027.

Vinodhini, V. and Das, N. 2010. Relevant Approach to Assess the Performance of Sawdust as Adsorbent of Chromium (VI) Ions from Aqueous Solutions. International Journal of Environmental Science and Technology. 7(1), 85-92. 